\title{
Saldar la cuenta. Teorías, políticas y estrategias expresivas de la literatura latinoamericana en español (1973-2018)*
}

\section{Settle up. Theories, Politics and Expressive Strategies in Latin American Literature in Spanish (1973-2018)}

Durante los días 17 y 19 de julio de 2017, tuve el placer de coordinar el simposio "Saldar la cuenta: debates, modos y discursos de la narración en la literatura de América Latina y el Caribe (1970-2016)" en el marco del IV Congreso Latinoamericano y Caribeño de Ciencias Sociales, celebrado en la ciudad de Salamanca. A grandes rasgos, el objetivo de esta reunión científica fue la reflexión teórica y estética suscrita por el contexto de los acelerados cambios que la experiencia de las dictaduras en América Latina desde los años sesenta en adelante había producido en el conjunto de los países del subcontinente a nivel político, económico, social y cultural. En particular, el simposio pretendió establecer un

\footnotetext{
* Esta presentación y las labores de coordinación de este dossier han sido realizadas al amparo de un contrato de investigación predoctoral de la Junta de Castilla y León, a través de la Consejería de Educación, en cofinanciación con el Fondo Social Europeo (Programa Operativo de Castilla y León) y se han desarrollado en el marco del Grupo de Investigación Reconocido "Estética y Teoría de las Artes (GESTA)" del Instituto de Iberoamérica de la Universidad de Salamanca.
} 
debate abierto acerca del modo en que esta circunstancia histórica, y más aún, la reapertura de un nuevo ciclo democrático — hoy en evidente crisis—-, determinó el surgimiento de específicas relaciones entre arte e historia que denotaban novedosas maneras de comprender el acto mismo y las posibilidades de narrar.

Una de las propuestas críticas más interesantes a este respecto, sin duda, ha sido expresada por Florencia Garramuño en su libro La experiencia opaca. Literatura y desencanto (2009), en el que aborda todo un conjunto de obras de las décadas de los setenta y ochenta del siglo XX caracterizadas por una "indistinción entre literatura y vida que tiende a desnaturalizar lo literario y sus funciones sublimatorias" (17). Este desprendimiento de la autonomía del texto literario trajo algunas consecuencias que son indispensables para explicar el devenir de la literatura latinoamericana del presente y, en particular, para captar la experiencia como materia narrativa. En líneas generales, el desencanto de lo moderno que estas escrituras comportan permite a Garramuño identificar como rasgo elemental la precariedad de lo real como totalidad y la consecuente voluntad de trabajar con la realidad como resto, entrañando, pues, "no tanto una pobreza de la experiencia sino la emergencia de otras formas de la experiencia, dramáticamente intensas" (35). El acto de "politización" de los escritores, por ende, también comenzaría a afectar a nuevos campos hasta ese momento impropios, desde la experimentación con el cuerpo y la sexualidad hasta la revalorización de lo cotidiano como espacio de reflexión.

No por casualidad, al otro lado del Atlántico, Michel de Certeau publicaba a comienzos de la década de los ochenta su trabajo La invención de lo cotidiano (1980), ensayo en el que abogaba por la necesidad de atender, más allá del estudio de los sistemas que Foucault había trazado, las prácticas del día a día para comprender en toda su extensión cómo el poder opera y qué resistencias encuentra: "Si es cierto que por todos lados se extiende y se precisa la cuadrícula de la 'vigilancia', resulta tanto más urgente señalar cómo una sociedad entera no se reduce a ella; qué procedimientos populares (también minúsculos y cotidianos) 
juegan con los mecanismos de la disciplina y sólo se conforman para cambiarlos" (XLIV).

Por otro lado, no puede dejar de advertirse que el acto de la narración condicionado por la experiencia de las dictaduras y el período posdictatorial es un hecho especialmente valioso para apreciar una grieta cuya sutura aún no se ha logrado, como Francine Masiello advirtió en El arte de la transición (2001). De acuerdo con sus conclusiones, los modos en los que muchos de los países del subcontinente se enfrentaron a los procesos de negociación con la historia traumática reciente "nos recuerdan que el pasado autoritario no ha sido totalmente desmantelado y también que las estrategias culturales básicas para explicar esta disyuntiva permanecen todavía intactas" (19) como parte de un sistema de autorreflexión que puede rastrearse en la tradición cultural de estos mismos países.

Lejos de aludir a un esencialismo reductor, sería conveniente leer en las palabras de Masiello la constatación de, al menos, dos hechos fundamentales. En primer lugar, la existencia de un conjunto de estrategias expresivas que se vienen desarrollando en el largo tiempo como recursos para abordar críticamente los sucesos de estos países en cada momento histórico, especialmente en aquellos marcados con mayor énfasis por el signo del autoritarismo. En segundo lugar, la vitalidad del pasado sobre el que se ejecuta una operación de apropiación que permite la reflexión anfibia, simultánea y superpuesta de varios tiempos históricos, lo que podría explicar, no totalmente pero sí en parte, un rasgo constitutivo de la "posmodernidad latinoamericana" — adjetivo que no niega, por lo demás, la capacidad de diálogo que el subcontinente ha mantenido y mantiene legítimamente con otras culturas - interesada en saldar la cuenta con un pasado que no pasa. Un pasado que instiga a los autores, quienes han decidido repensar la historia colonial americana, los procesos de independencia del siglo XIX o los discursos de la modernización de los años cincuenta y sesenta, entre otros asuntos. En este sentido, el efecto de los procesos posdictatoriales ha sido, junto a la ya comentada aparición de una nueva relación entre realidad y literatura, lo que hace posible hablar de "otra dimensión más seria de la experiencia” (Masiello 25). 
Esta panorámica, sin duda incompleta pero útil para entender los propósitos de este dossier, debería aludir a continuación a un asunto apenas sugerido en los párrafos anteriores, pero crucial en el devenir del arte. A saber, la extraterritorialidad de la literatura latinoamericana desde los años noventa hasta nuestros días, una suerte de "narrar sin fronteras" cuya universalidad se encuentra "marcada por el rechazo a los prejuicios nacionalistas y comprometida exclusivamente con la ficción" (Noguerol 32). Más allá de los cauces que esta vocación universalista de la literatura ha alcanzado, no puede obliterarse el hecho de que el origen de muchas de estas propuestas se encuentra en la experiencia del exilio - de nuevo, entendido de forma amplia, desde el ostracismo político de los setenta y ochenta hasta las desterritorializaciones voluntarias en un contexto de globalización del saber y de sus circuitos de desplazamiento.

No es de extrañar, pues, que todos los elementos aludidos en este breve recuento apunten hacia dos circunstancias esenciales para comprender la literatura latinoamericana del presente. El primero de ellos, campo de especialización por antonomasia en las últimas décadas, el trabajo con y sobre la memoria. Las obras literarias de mayor valor y eficacia en los procesos de negociación con la memoria — algunas de ellas exploradas en este dossier — se articulan a partir de lo que Idelber Avelar (2000) ha denominado "memoria metonímica", aquella que no procede por sustitución de lo perdido, sino a través de un trabajo de duelo como "práctica afirmativa" que permite desentrañar los lineamientos del presente con la historia — reciente o lejana-, con el origen. En este sentido, debe destacarse la "intempestividad" de la literatura latinoamericana como rasgo fuerte de muchos autores que, siguiendo a Avelar, "piensan el fundamento del presente, desgarrándose de él para vislumbrar lo que este presente tuvo que ocultar como tal —lo que, en otras palabras, a ese presente le falta." (34)

El segundo de los aspectos primordiales para entender el estado de la literatura latinoamericana actual es la violencia, circunstancia fácilmente constatable si prestamos atención al ámbito mayoritario en que ha tomado forma: el espacio de lo cotidiano. Es aquí donde la deuda contraída por la literatura del 
subcontinente con las poéticas de los años ochenta se manifiesta con mayor contundencia. Además, una condición soslayada hasta ahora en esta introducción, pero de enorme elocuencia, es el papel preponderante que la "urbanofobia” (Aínsa, 2013) empezó a asumir en la representación literaria de la ciudad como espacio público, instancia a partir de la cual "La transformación urbana quedó reducida a metáforas del deterioro y la demolición.” (Aínsa 59). En definitiva, espacio de violencia en íntima relación con el desencanto de los discursos modernizadores de las décadas previas.

No obstante, sostenemos que la manera en que la literatura latinoamericana representa hoy la violencia no habría podido tener lugar sin la aparición de estas propuestas de reformulación de la memoria en los últimos años. Así pues, el valor de las poéticas de los ochenta y la ampliación extraordinaria de las fronteras extraterritorialidad, escritura transnacional - consiguen hallar a través de la suma del producto de la memoria - y, en mayor medida, la constatación "metonímica" de su errática formulación - el objetivo de alcanzar el mayor grado de amplitud a la hora de "vislumbrar lo que este presente tuvo que ocultar". En este sentido, proponemos aquí que la literatura latinoamericana ha entrado, a través de un significativo número de novelas y ensayos, en fase de "narcisismo abyecto", término que debemos precisar.

A partir de los años noventa, se ha identificado la presencia de un "narcisismo narrativo" en muchas obras del subcontinente, concepto con el que se alude a "la abundancia de monólogos y elipsis, la ausencia de diálogos, el predominio del narrador homodiegético y el triunfo de formas fragmentarias" (Noguerol 30). Por no hablar, en otro sentido, de la pervivencia del paradigma del "narcisismo posmoderno", caracterizado por la explosión de actos comunicativos. En palabras de Gilles Lipovetsky (1983), se trata de "Comunicar por comunicar, expresarse sin otro objetivo que el mero expresar [...], el narcisismo descubre aquí como en otras partes su convivencia con la desubstancialización posmoderna, con la lógica del vacío" (15). Por el contrario, el elevado número de novelas y ensayos que tematizan la enfermedad del espacio cotidiano y de los cuerpos - frente a ese 
corpus que en la década de los ochenta "politizaba" la existencia a fuerza de experimentar - entraña la exigencia de representación de una violencia bruta que, lejos de hablar del autoritarismo de las dictaduras o del horror que jalona algunos episodios del pasado, se ha encarnado en las relaciones interpersonales, hablando de una nueva condición del sujeto que la literatura afronta sin reparos a través de una lengua que muestra el rictus de lo "abyecto", retorciéndose entre el rechazo y la tentación de permanecer.

Con seguridad, y pese a la responsabilidad que otros factores hayan podido tener en este devenir, ha sido a partir del empuje que en la última década ha experimentado el tejido social gracias al activo papel del feminismo cuando hemos empezado a advertir de forma colectiva lo que nunca se ve: la magnitud estructural de la violencia. Así pues, que los escritores empezaran a inocular esa violencia en sus narraciones depositándola en los cuerpos de quienes la encarnan (activa o pasivamente) hasta hacerlos indistinguibles, era solo cuestión de tiempo. Del mismo modo que la apertura extraordinaria de este "narrar sin fronteras", que tanto asombro provocó en los escritores de los años noventa y principios de la primera década del siglo XXI, no tardaría en traducirse en la evidencia de que los elementos estructurales del sistema pueden moverse con rapidez y llegar a cualquier rincón del planeta en apenas segundos, gracias a los medios técnicos de los que disponemos. Por eso, tampoco es de extrañar que una parte significativa de la nómina general de autores de esta nueva literatura latinoamericana volcada hacia la narración de la violencia sin paliativos esté representada por mujeres. Pero, ¿en qué consiste este "narcisismo abyecto"?

En su ensayo Poderes de la perversión (1980), Julia Kristeva se aproximó con detenimiento al estudio de las relaciones entre el narcisismo y la abyección, partiendo de la consideración de lo abyecto como elemento expulsado que fuerza una consecuente expulsión (frecuentemente sintomática) del yo. En líneas generales, el continuo hostigamiento que la abyección produce en el yo (en la identidad) hasta desestabilizarlo, convoca a los escritores a representar un conjunto de actos simbólicos y materiales que provocan en muchos personajes y, desde 
luego, en el lector, una náusea, un vómito o un instinto de apartar la mirada. El cadáver, que Avelar consideraba símbolo perfecto de la alegoría de la derrota, se ha convertido ahora en materia narrativa idónea para la formulación de una violencia que nos reclama a todos. Un cadáver no sólo como muerte sino como desaparición límite de la identidad, la amenaza constante de desidentificación a la que tantos personajes se ven abocados, pues incluso el privilegio simbólico que las relaciones más sagradas — las de sangre — tenían se ha perdido. La posibilidad del cadáver acecha de forma constante siguiendo una senda en la que violencia y violación se identifican como caras constitutivas de la misma lógica. En último término, el cadáver ha dejado de ser improfanable, y con ello, la alegoría o la ruina han perdido su aura de herramientas preferenciales, en un movimiento de descrédito de cualquier tipo de institucionalización de la memoria. Desde este planteamiento, apunta Kristeva, la abyección es una "crisis narcisista" en la que "lo abyecto es la violencia del duelo de un 'objeto' desde siempre perdido.” (24)

Se aprecia aquí con mayor claridad adónde queremos llegar y qué hipótesis manifestamos. A saber, el surgimiento de nuevos cauces de representación de un escenario en el que la amplitud estructural de la violencia se ha hecho más evidente que en toda la historia moderna de Occidente. Así pues, la nueva crisis del "yo" motivada por este desequilibrio explica que la abyección haya entrado con fuerza en la narración a través de espacios cada vez más íntimos y cotidianos, determinando la necesidad de hablar de una nueva etapa que aquí hemos denominado, a falta de un concepto más adecuado, "narcisismo abyecto". Esta crisis de identidad ha sido ratificada por multitud de intelectuales contemporáneos, pero es significativa la reciente publicación del ensayo Desaparecer de sí. Una tentación contemporánea (2015), en el que David Le Breton estudia diversas figuraciones del borrado de la identidad y de la presencia social del yo, voluntarias o involuntarias, momentáneas o prolongadas — desde los hikikomori hasta la ingesta de alcohol u otras drogas; desde los trastornos de personalidad múltiple a las fugas adolescentes: "No se trata de una excentricidad ni una patología, sino una expresión radical de libertad: la del rechazo a colaborar manteniéndose a distancia 
o rehuyendo la parte más restrictiva de la identidad en el seno del vínculo social”.

El equilibrio de este vínculo, amenazado por una necesaria reconfiguración de "lo que este presente tuvo que ocultar", ha impulsado el surgimiento de este violento "narcisismo abyecto" que nos impele por la fuerza a tener que enfrentarnos a la visión de lo que había permanecido disimulado en aras del correcto funcionamiento de la maquinaria social. Adónde nos lleve esta literatura no lo podemos saber con certeza. Por el momento, bastaría con hacernos cargo de la necesidad de repensar el papel indiscutible del escritor como nuevo agente "ético", pues la abyección de la literatura latinoamericana del presente en absoluto comporta el abandono acrítico hacia la escatología sino, por el contrario, una llamada a retomar de forma colectiva el debate sobre el modo en que el tejido social podría recomponerse tras la caída de las últimas máscaras, obligándonos a comparecer en el ejercicio de saldar la cuenta una vez más.

Estos fueron los aspectos más urgentes y significativos que el simposio organizado en el año 2017 pretendió abordar. Asimismo, es un hecho indiscutible que los trabajos aquí reunidos se ocupan de todas las vertientes aludidas en esta presentación, desde los años setenta hasta nuestros días. De este modo, en la medida en que la panorámica que acabamos de trazar haya sido de utilidad, también lo serán los trabajos que siguen a continuación.

En primer lugar, la doctora Eliana Urrego Arango, en su artículo titulado “Nos llevó el ensanche': Medellín en las novelas urbanas de Manuel Mejía Vallejo", se aproxima a la representación de la ciudad de los años setenta y señala como su rasgo más sobresaliente "el temor a perderlo todo definitivamente, a extraviarse en el olvido, esa imposibilidad de volverse a narrar que lo sepulta todo". Desde este planteamiento, las novelas de Mejía Vallejo serían útiles para demostrar que la modernización, sentida como proceso artificial y extraño, provocó el desarraigo y la hostilidad de un espacio arrasado, ante el cual la única fórmula de resistencia es, a pesar del tono nostálgico, el trabajo con la memoria como acto de reconstrucción y cuestionamiento del ideal del progreso. 
A continuación, la doctora Cristina Pérez Múgica firma el artículo "“Con los pobres de la tierra quiero yo mi suerte echar...': la figura del intelectual-lumpen en las obras de Guillermo Rosales y Pedro Juan Gutiérrez”, en el que propone una teoría interpretativa del papel del intelectual en estrecha relación con los márgenes sociales en los "adquiere unos rasgos propios y actúa como portavoz o artífice de una cultura paralela a la oficial”. Las novelas de Rosales y Gutiérrez, por tanto, confirmarían la estrecha relación existente entre el giro hacia los márgenes y las condiciones de desencanto político con la Revolución Cubana y las democracias liberales, así como sus posibilidades de contestación a las lógicas que fundaron las utopías de un nuevo orden.

En el tercer artículo de este dossier, titulado "Reescrituras de la tragedia en el teatro latinoamericano contemporáneo. El caso Antígona”, la doctora Lía Noguera analiza un conjunto amplio de obras dramáticas que trabajan sobre este mito clásico demostrando que el acto de apropiación cultural que operan tiene el objetivo de saldar la cuenta con la historia de cada país como "comunidad imaginada" y asimilar el trauma residual que estos mismos hechos comportan en el presente, determinando la contingencia de cada nación para seguir siendo o no un símbolo estable y representativo de quienes la habitan.

En "Estrategias para desacralizar y reescribir la (pos)memoria y la identidad: mercado editorial, autoficción y parodia en 76 y Los topos de Félix Bruzzone", el investigador Jonatán Martín Gómez trabaja con la hipótesis de que estas obras proponen un nuevo modo de aproximación a los recientes sucesos históricos argentinos gracias a la transformación del imaginario y de las fórmulas retóricas y discursivas utilizadas hasta ese momento para enfrentar el trauma. En rigor, la novedad de este tratamiento residiría en la utilización de la parodia y la autoficción, así como algunos recursos propios de géneros literarios populares, en favor de dos operaciones: la identificación de los límites de la representación y de la variedad de operaciones que la memoria admite y, por otro lado, la demostración de las continuidades entre violencias del presente y el pasado. 
Por su parte, Pedro Mármol Ávila acomete en su estudio "Violencia y multiplicidad narrativa en Bioy, de Diego Trelles Paz" un análisis del juego de diferentes planos temporales y superposiciones de voces narrativas que constituye esta obra. A través de estos recursos, la novela nos permite constatar la íntima relación existente entre la violencia y el hecho de su representación, en la medida en que el texto lleva al límite sus elementos estructurales para visibilizar la "diversidad de perspectivas" que explican los orígenes y la magnitud de una violencia que, para ser narrada, solicita un código propio que Trelles Paz construye exprofeso.

El sexto artículo, firmado por la doctora Raquel Crespo-Vila, lleva por título “El entenado, de Juan José Saer: 'nueva crónica de Indias', 'nueva novela histórica', 'metaficción historiográfica', 'ficción y de archivo' y 'novela neobarroca". Más allá de la primacía de cualquier hipótesis, el valor indiscutible de este trabajo reside en dos aspectos fundamentales. Por un lado, el bien documentado debate que su autora mantiene sobre la productividad, las limitaciones y las implicaciones de diferentes marcos teóricos que han intentado dar cuenta de la eclosión de la historia en la narrativa del subcontinente a partir de los años ochenta. Por otro lado, la constatación del sitio preferencial que ocupan la intertextualidad y la metaficción como elementos constitutivos mínimos de estas aproximaciones teóricas y, por tanto, del modo en que la historia se ha instalado en la narrativa reciente.

El último título de este dossier, "La mirada borrosa: poéticas del desenfoque y visiones oblicuas en la narrativa hispánica contemporánea", testimonia uno de los cauces por los que discurre en la literatura latinoamericana actual el propósito de desvelar "lo que este presente tuvo que ocultar". Marta Pascua Canelo, su autora, emprende aquí el análisis de un conjunto significativo de obras escritas por mujeres caracterizado por la tematización de "desórdenes ópticos". Las conclusiones provisorias de este trabajo confirmarían, según la investigadora, el surgimiento de una corriente de crítica hacia los modos canónicos de legitimación del 
conocimiento en un contexto de creciente destitución de la hegemonía del sistema patriarcal.

Antes de terminar, me gustaría agradecer, en primer lugar, la intervención de todos los investigadores que formaron parte del simposio que dio origen a este dossier, y muy especialmente a aquellos que, armados de paciencia, comparecen hoy aquí, dos años y medio más tarde, con artículos que han sido reformulados gracias a la atención que sus autores han prestado a las últimas aportaciones de la crítica literaria, integrándolas de forma rigurosa. En segundo lugar, me gustaría agradecer el interés demostrado por todos aquellos doctores y no doctores, colegas y amigos, que decidieron enviar sus propuestas para este dossier, sin las cuales el intento de abordar la literatura del subcontinente habría resultado mucho más estéril. Agradezco también su labor a los revisores que con tanto esmero se volcaron en la tarea de hacer que estos trabajos brillasen con más intensidad. Para finalizar, quiero reconocer la implicación del consejo editorial de la revista Catedral Tomada, cuyos miembros acogieron este proyecto desde el comienzo, sin condiciones y con enorme diligencia.

En Salamanca, 17 de julio de 2017 - 15 de diciembre de 2019. (Trigésimo sexto aniversario de la creación de la Comisión Nacional sobre la Desaparición de Personas (CONADEP) en Argentina). 


\section{Bibliografía}

Aínsa, Fernando. "La ciudad entre la nostalgia del pasado y la visión apocalíptica". Utopías urbanas. Geopolíticas del deseo en América Latina. Gisela Heffes, editora. Frankfurt am Main: Vervuert, 2013, pp. 49-86.

Avelar, Idelber. Alegorías de la derrota. La ficción postdictatorial y el trabajo del duelo. Providencia: Cuarto Propio, 2000.

Breton, David Le. Desaparecer de sí. Una tentación contemporánea. Madrid: Siruela, 2018 [2015].

Certeau, Michel de. La invención de lo cotidiano. Artes de hacer I. México, D.F.: Universidad Iberoamericana, 1996 [1980].

Garramuño, Florencia. La experiencia opaca. Literatura y desencanto. Buenos Aires: Fondo de Cultura Económica, 2009.

Kristeva, Julia. Poderes de la perversión. Ensayo sobre Louis-Ferdinand Céline. México, D.F.: Siglo XXI, 1988 [1980].

Lipovetsky, Gilles. La era del vacío. Ensayos sobre el individualismo contemporáneo. Barcelona: Anagrama, 2017 [1983].

Masiello, Francine. El arte de la transición. Buenos Aires: Grupo Editorial Norma, 2001.

Noguerol Jiménez, Francisca. "Narrar sin fronteras". Entre lo local y lo global. La narrativa latinoamericana en el cambio del siglo (1990-2006). Jesús Montoya Juárez y Ángel Esteban, editores. Madrid; Frankfurt am Main: Iberoamericana; Vervuert, 2008, pp. 19-33. 